
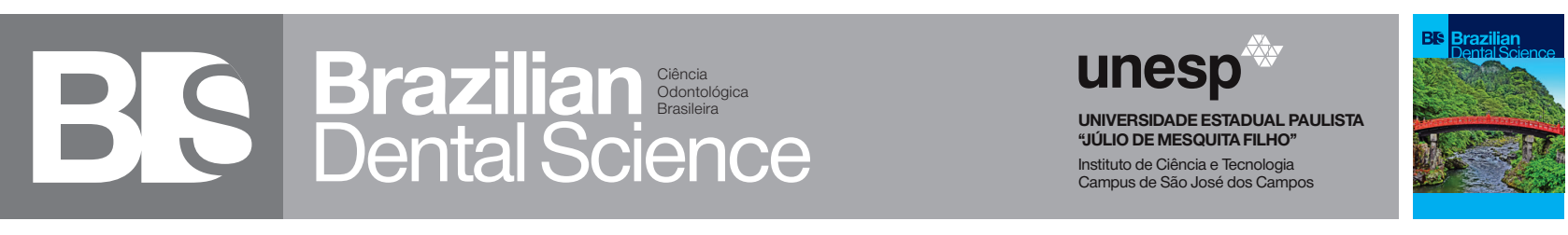

\title{
Changes in dental esthetic perceptions of patients subjected to in- office tooth bleaching
}

Mudanças nas percepções estéticas odontológicas de pacientes submetidos a clareamento dental de consultório

Karla Danielly Alves SOARES ${ }^{1}$, Edmundo Marques do NASCIMENTO-JÚNIOR ${ }^{2}$, Aline Carvalho PEIXOTO ${ }^{3}$, André Luis FARIA-e-SILVA ${ }^{4}$

1 - Private clinic - Aracaju - SE - Brazil.

2 - Graduate Program in Dentistry - Federal University of Sergipe - Aracaju - SE - Brazil.

3 - Graduate Program in Health Sciences - Federal University of Sergipe - Aracaju - SE - Brazil.

4 - Department of Dentistry - Federal University of Sergipe - Aracaju - SE - Brazil.

\section{ABSTRACT}

Objective: This study evaluated changes in the esthetic perceptions of patients subjected to inoffice tooth bleaching. Material and Methods: Fifty participants included in a clinical trial evaluating the in-office tooth bleaching answered two questionnaires about their dental esthetic perceptions. The participants answered the Orofacial Esthetic Scale (OES) questionnaire and the Psychosocial Impact of Dental Aesthetics Questionnaire (PIDAQ) before and after treatment. The average scores observed at baseline were compared with those recorded after tooth bleaching using the paired t-test or the Wilcoxon signed rank test $(\alpha=0.05)$. Results: Improvement in tooth color (reduction of 5.1 shade guide units) had a positive impact on patients' perceptions. According to PIDAQ, tooth bleaching significantly increased the psychological impact and dental selfconfidence; and reduced esthetic concerns. The OES demonstrated improvements in participants' satisfaction for all questions, except for the one on "facial appearance". However, higher effect size was observed for the question related to tooth color, as expected. Conclusion: Tooth bleaching was associated with an overall improvement in dental esthetic perception, even when only tooth color was affected.

\section{KEYWORDS}

Patient-reported outcomes; Randomized Controlled clinical trials; Tooth bleaching.

\section{RESUMO}

Objetivo: Este estudo avaliou mudanças nas percepções estéticas de pacientes submetidos a clareamento dental de consultório. Material e Métodos: Cinquenta pacientes incluídos em um ensaio clínico avaliando clareamento dental de consultório responderam a dois questionários sobre suas percepções estética odontológicas. Os participantes responderam ao questionário de escala estética orofacial (EEO) e o questionário de impacto psicossocial da estética orofacial (PIDAQ) antes e após o tratamento. As médias dos escores no início do tratamento foram comparados com aqueles mensurados após o clareamento usando o teste-T pareado ou de Wilcoxon $(\alpha=0,05)$. Resultados: Melhora na cor dental (redução de 5,1 unidades da escala de cor) teve um impacto positivo nas percepções dos pacientes. De acordo com PIDAQ, o clareamento dental significativamente aumentou o impacto psicossocial e autoconfiança dental, e reduziu as preocupações estéticas. O EEO demonstrou melhora na satisfação dos participantes para todas as questões, exceto para a de "aparência facial". Entretanto, maior efeito foi observado para a questão relacionada à cor dos dentes, como esperado. Conclusão: O clareamento dental foi associado com um aumento geral na percepção estética odontológica, mesmo que apenas a cor dos dentes foi afetada.

\section{PALAVRAS-CHAVE}

Desfechos centrados no paciente; Ensaio clínico controlado randomizado; Clareamento dental. 


\section{INTRODUCTION}

A n esthetic smile can strongly affect patients' facial appearance, improving their selfesteem and social relations [1]. Previous studies have shown that more than $30 \%$ of Americans report some degree of dissatisfaction with the color of their teeth [2], vis-à-vis 20\% among English individuals [3]. In fact, tooth bleaching has been used not only to treat severe cosmetic changes in tooth color, but also to improve the satisfaction of patients with their smile, since esthetic requirements have increased in our society [4]. Therefore, although smile attractiveness is related to several factors including shape and position of the teeth, tooth color has a strong effect on the ultimate esthetic and social perceptions, as brighter teeth are usually related to good oral health status [5].

Tooth bleaching is a noninvasive technique for treating tooth discolorations and presents a high success rate in obtaining the desirable tooth color [6]. The bleaching effect is achieved due to free radicals generated by the breakdown of peroxide, which degrade the organic structure of dentin, promoting its lightening [7]. Tooth bleaching can be achieved by using either at-home techniques - when the patient uses a hydrogen peroxide-filled tray at home, or in-office procedures, by applying high-concentration bleaching agents over the discolored teeth [8]. Additionally, bleaching agents, including strips, paint-on, or hydrogen peroxide-filled trays, can be purchased over the counter [9]. Despite the similar results obtained by patients who used at-home and inoffice techniques $[8,10,11]$, those performed in-office are widely preferred by patients who are not willing to use trays or who want to avoid any contraindication associated with at-home techniques, such as gastrointestinal disorders [12].

Most clinical trials evaluating tooth bleaching procedures have focused only on color changes measured through shade guides or spectrophotometry. It also has been demonstrated that in-office bleaching is able to change five shade guide units, on average, or achieve a $\Delta \mathrm{E}$ around 16. An interesting previous study evaluating color difference thresholds in dentistry found that at least half of the laypersons included in the study considered color differences larger than 2.9 to be significantly important [13]. Therefore, color changes achieved with in-office bleaching are likely to be perceived by patients, but improvement in esthetic perception can differ from merely noting color changes. Esthetic perceptions are also affected by factors such as levels of social competence, intellectual ability, psychological adaptation, and sociability [14]. Accordingly, the aim of this study was to evaluate possible changes in esthetic perception of patients subjected to in-office tooth bleaching. The hypothesis was that the tooth color change affects the overall dental esthetic perceptions of patients.

\section{MATERIALS AND METHODS}

This study was part of a double-blind, randomized, cross-over, controlled clinical trial that assessed the effect of prior use of Cicladol ${ }^{\circledR}$ (piroxicam-beta-cyclodextrin) on the reduction of sensitivity caused by tooth bleaching with 35\% hydrogen peroxide (Whiteness HP Maxx, FGM, Joinvile, SC, Brazil). This trial was registered at clinicaltrials.gov under protocol \# NCT03153657 and was approved by the local Human Research Ethics Committee (CAAE: 50511415.1.0000.5546). All participants included in the study signed the informed consent form. The study was conducted at the Dental School of the local University from May 2017 to August 2017.

Fifty participants were included (Figure 1 ) in the trial after sample size calculation performed for the main outcome (reduction of tooth sensitivity risk) and according to the following inclusion criteria: any individual aged over 18 years interested in tooth bleaching, 
with all upper anterior teeth, and color equal to or darker than $2.5 \mathrm{M} 2$ (VITA Bleachedguide

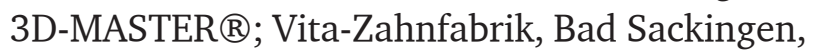
Germany). The exclusion criteria were: presence of restorations or endodontic treatment in the upper anterior teeth; history of previous tooth bleaching treatment; smoking; history of any prior general and/or oral health condition that could put patients at risk during the study; pregnancy or lactation; any dental treatment planned to be performed during the course of the study; generalized periodontal disease; complex intrinsic staining related to tetracycline, fluorosis, or hypocalcification; previous dental sensitivity; allergic reaction to the components of the anti-inflammatory drug used or any clinical alteration that contraindicated its use; and continuous use of any anti-inflammatory drug or anti-oxidants.

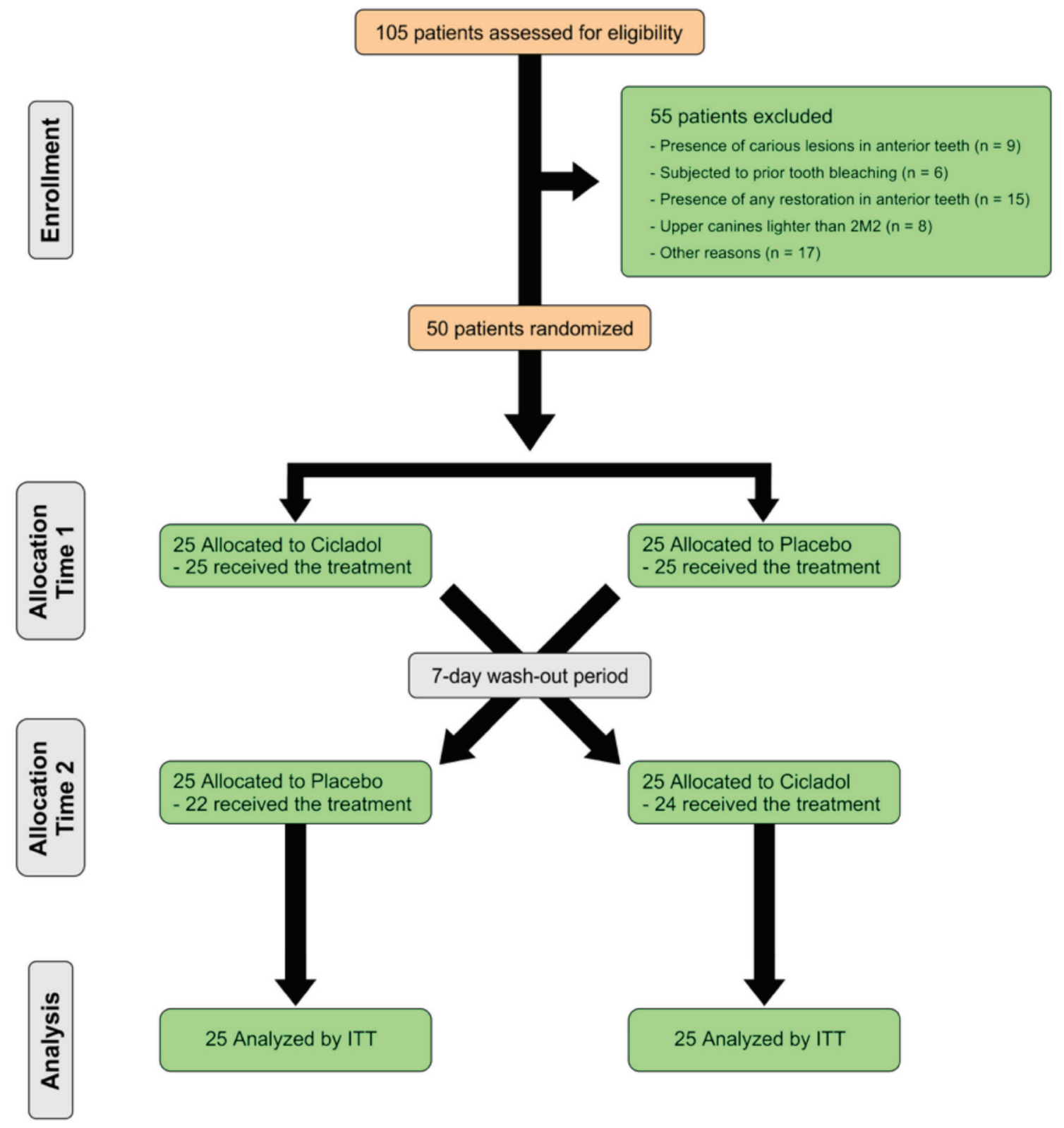

Figure 1 - Flowchart of the clinical trial. 
Prior to bleaching, the patients were instructed to complete the Orofacial Esthetic Scale (OES) questionnaire and the Psychosocial Impact of Dental Aesthetics Questionnaire (PIDAQ) - Appendix. The OES is a questionnaire that reflects esthetic values perceived by the patient by measuring the impact of seven aspects related to the esthetics of the face, lip, tooth, and mouth. The PIDAQ is a questionnaire with 23 questions separated into four domains: 1) esthetic concern (3 questions); 2) psychosocial impact (6 questions); 3) social impact (8 questions); and 4) dental self-confidence (6 questions). The questionnaires were self-completed by the patients. Furthermore, the color of upper canines was assessed by a single calibrated evaluator (Kappa coefficient higher than 0.80) using the VITA Bleachedguide 3D-MASTER $®$.

Regardless of whether the patient was treated with anti-inflammatory drugs or placebo, the tooth bleaching protocols were the same. After prophylaxis, the teeth to be bleached were isolated using a rubber dam (Top Dam, FGM, Joinville, SC, Brazil) and the patients were subjected to in-office dental bleaching with a 35\% hydrogen peroxide whitening agent (Whiteness HP Maxx, FGM, Joinvile, SC, Brazil), following the manufacturer's instructions. The bleaching agent was applied to the buccal surface and allowed to act for 45 minutes without any replacement. The procedures were repeated after one week, and the OES and PIDAQ were reapplied seven days after the last bleaching session. The color of upper canines was also evaluated at the time.

From the 50 participants included in the study, four who did not show up for the additional appointments and data of OES and PIDAQ obtained at baseline were repeated based on the intention-to-treat analysis. Scores from 0 (do not agree) to 4 (completely agree) were attributed to the answers given to each question and the total scores for each domain - "esthetic concern" (3 items), "psychological impact" (6 items), "social impact" (8 items), and "dental self-confidence" (6 items) - were calculated. The total scores recorded at each assessment time were also calculated. The scores observed at different assessment times were compared by the paired t-test. PIDAQ scores were not normally distributed (Shapiro-Wilk test) for "social impact" and the non-parametric Wilcoxon signed rank test was used. The effect size for each domain and the total scores were calculated by the difference between the means of the observed effect and the means observed at baseline.

For each question in the OES, the means observed at baseline were compared to those recorded after tooth bleaching by the paired t-test. The Wilcoxon signed rank test was used when data did not present a normal distribution (ShapiroWilk test). The effect size for each question was calculated using the same procedure described for PIDAQ. Data analysis was performed using the SigmaStat v.3.5 software package (Systat Software Inc., Chicago, IL, USA). The significance level was set at $\alpha=0.05$ for all analyses.

\section{RESULTS}

Participants' ages averaged 25.8 years (standard deviation of 5.6), with a predominance of women (66.0\%) and upper canines with an average score of 10.7 (standard deviation of 1.3), corresponding to shade $4 \mathrm{M} 2$ in the VITA Bleachedguide 3D-MASTER $\AA$. After tooth bleaching, the average score dropped to 5.6 (standard deviation of 1.3), accounting for an average reduction of 5.1 shade guide units.

The findings obtained with the PIDAQ are presented in Table 1. Tooth bleaching significantly increased psychological impact and dental self-confidence, reduced the esthetic concern, but did not affect the social impact of tooth appearance. A stronger effect of tooth bleaching was observed for the esthetic concern domain. However, the overall perception of participants was not modified by tooth bleaching. Table 2 shows the results for OES. Except for "facial appearance," there were improvements in participants' satisfaction according to all answers, and a larger effect was observed for the question on tooth color. A significant effect on OES total score was also observed. 
Table 1 - Means (95\% confidence interval) of answers to each domain of the PIDAQ questionnaire measured at baseline and after tooth bleaching

\begin{tabular}{|c|c|c|c|c|c|}
\hline Domains & Baseline & After bleaching & P-value & Observed effect & Effect size \\
\hline $\begin{array}{l}\text { Esthetic Concern } \\
\text { ( } 3 \text { items) }\end{array}$ & 4.1 (3.3 to 4.9$)$ & 2.3 (1.7 to 2.9$)$ & $<0.001$ & $-1.8(-2.8$ to -0.8$)$ & -0.46 \\
\hline $\begin{array}{l}\text { Psychological Impact } \\
\text { (6 items) }\end{array}$ & 8.0 (6.9 to 9.1$)$ & 9.3 (8.2 to 10.4) & 0.030 & $1.3(-0.3$ to 2.9$)$ & 0.16 \\
\hline $\begin{array}{l}\text { Social Impact } \\
\text { (8 items) }\end{array}$ & 8.1 (6.8 to 9.4 ) & 7.6 (6.5 to 8.7) & $0.712^{\star}$ & $-0.5(-2.2$ to 1.2$)$ & -0.06 \\
\hline $\begin{array}{l}\text { Dental Self-confidence } \\
\text { (6 items) }\end{array}$ & 9.6 (8.7 to 10.5) & 8.1 (7.2 to 9.0$)$ & 0.003 & $-1.5(-2.8$ to -0.2$)$ & -0.16 \\
\hline Overall perception & 29.9 (26.9 to 32.9 ) & 27.3 (24.6 to 30.0 ) & 0.073 & $-2.6(-6.6$ to 1.4$)$ & -0.09 \\
\hline
\end{tabular}

* Data did not present normal distribution (Shapiro-Wilk test) and were analyzed by the Wilcoxon signed rank test. PIDAQ - Psychosocial Impact of Dental Aesthetics Questionnaire

Table 2 - Means (95\% confidence interval) of answers to each question of the OES questionnaire measured at baseline and after tooth bleaching

\begin{tabular}{|c|c|c|c|c|c|}
\hline Questions & Baseline & After bleaching & P-value & Observed effect & Effect size \\
\hline Your facial appearance & 7.5 (7.1 to 7.9$)$ & 7.9 (7.5 to 8.3$)$ & $0.135^{\star}$ & $0.4(-0.2$ to 1.0$)$ & 0.06 \\
\hline Appearance of your facial profile & $6.6(6.2$ to 7.0$)$ & 7.6 (7.1 to 8.1$)$ & $0.007^{\star}$ & 1.0 (0.4 to 1.6$)$ & 0.16 \\
\hline $\begin{array}{l}\text { You mouth's appearance (smile, lips, and } \\
\text { visible teeth) }\end{array}$ & $6.3(5.7$ to 6.9$)$ & 8.1 (7.6 to 8.6) & $<0.001^{*}$ & 1.8 (1.1 to 2.5$)$ & 0.29 \\
\hline Appearance of your row of teeth & 6.1 (5.6 to 6.6$)$ & 7.6 (7.1 to 8.1$)$ & $« 0.001$ & $1.5(0.8$ to 2.2$)$ & 0.26 \\
\hline Shape/form of your teeth & $6.9(6.4$ to 7.4$)$ & 7.7 (7.2 to 8.2) & 0.002 & $0.8(0.1$ to 1.5$)$ & 0.12 \\
\hline Color of your teeth & 4.7 (4.1 to 5.3$)$ & 8.3 (7.8 to 8.8$)$ & $<0.001$ & 3.6 (2.8 to 4.4$)$ & 0.78 \\
\hline Your gum's appearance & 7.0 (6.4 to 7.6$)$ & 8.4 (7.9 to 8.9$)$ & $<0.001^{*}$ & 1.4 (0.6 to 2.2$)$ & 0.21 \\
\hline $\begin{array}{l}\text { Overall, how do you feel about your face, } \\
\text { your mouth, and your teeth? }\end{array}$ & $7.1(6.8$ to 7.4$)$ & 8.3 (7.9 to 8.7$)$ & $<0.001^{*}$ & $1.2(0.7$ to 1.7$)$ & 0.17 \\
\hline OES total score & $52.0(49.6$ to 54.4$)$ & $64.1(61.0$ to 67.2$)$ & $<0.001$ & $12.1(8.2$ to 16.0$)$ & 0.23 \\
\hline
\end{tabular}

* Data did not present normal distribution (Shapiro-Wilk test) and were analyzed by the Wilcoxon signed rank test. OES - Orofacial Esthetic Scale.

\section{DISCUSSION}

Most studies on tooth bleaching only evaluate tooth sensitivity or color changes $[3,6]$, but the patients' perceptions of their dental esthetics are of great importance for the design of clinical protocols $[3,15,16]$. In this study, we evaluated the effect of in-office tooth bleaching on patients' perceptions of their own dentofacial esthetics, as well as their opinion about smile. Interestingly, tooth bleaching that modified only tooth color also affected patients' perception of other aspects related to smile.
Studies evaluating patients' perceptions of dental procedures are a relatively new concern in dentistry [17]. Among the questionnaires used for these evaluations, most studies have used those that associate the impact of dental treatments on oral health-related quality of life. Furthermore, more specific questionnaires that assess people's perceptions of the impact of oral conditions on their well-being have been developed $[6,18]$ and standards have been created for the translation and adaptation of these questionnaires to different cultures [19-22]. Both OES and PIDAQ are questionnaires widely used to assess the patients' 
perception of esthetic concerns and their impact on quality of life. The use of OES is well established in the dental literature $[19,23,24]$ since it reflects the esthetic values perceived by patients associated with seven aspects of facial esthetics, including face, lip, teeth, and mouth. While this questionnaire was initially designed to be used in orthodontics, including several questions that evaluate perceptions, with no assessment of tooth color, its use for the evaluation of changes caused by tooth bleaching has yielded interesting results. The Brazilian version of PIDAQ was validated by a prior study [25], while the validation of OES was not published yet [unpublished data].

Among the aspects evaluated in the OES questionnaire, changes in tooth color, as expected, had the highest impact on participants' perception, with a 78\% increase in the scores related to this question. This high effect size is due to the fact that the patients included willing to obtain a smile with whiter teeth. In fact, the color evaluation performed in the present study showed that canines had a reduction of around 5 shade guide units as a result of tooth bleaching, indicating that the effectiveness of the bleaching procedure was perceived by the participants. It is important to emphasize that the general esthetic perception also improved, showing that tooth color largely affects smile esthetics, as demonstrated by previous studies [5,26-29]. Interestingly, in addition to the perception of tooth color improvement, the OES questionnaire also showed improvement in participants' perception of their facial appearance, mouth (including lips, smile, and visible teeth), gums, and tooth shape. Since bleaching procedures only modify tooth color, these findings might be explained by increased attention of patients to their overall facial esthetics. As dental procedures were performed, it is reasonable to think that patients began to analyze more frequently other aspects related to their smile that had been overlooked before. However, the effect sizes observed for questions related to other oral esthetic perceptions ranged from 16 to $29 \%$ and were much lower than those observed for tooth color.

The PIDAQ revealed that tooth bleaching reduced the participants' esthetic concern, with a $46 \%$ reduction in the scores related to that domain, showing that the participants were less concerned with their dental aesthetic. In addition, there was an average increase of $16 \%$ in the scores related to the psychological impact domain, and these results indicates a positive impact of whiter teeth on this domain. These results can be explained by the fact that smile attractiveness impacts on social ability, increasing the inclusion and acceptance of patients in society [29] and providing positive judgment, since beautiful people are more confident in relationships, get better jobs with higher salaries, and make friends more easily [31]. Regarding "dental self-confidence," the results demonstrated an average reduction of $16 \%$ in the scores. In this domain, the reduction in scores could indicate, for instance, the participant was less concerned with improving his/her smile or with smiling in public, corroborating the positive effect of tooth bleaching. Therefore, the results obtained from PIDAQ suggest that esthetic treatments, such as tooth bleaching, can improve patients' personal satisfaction and, ultimately, their quality of life.

Despite their importance, studies on patients' perception of the outcomes of clinical treatment present some difficulties. In our study, contacting patients after the completion of the bleaching procedure was a problem. When the required tooth color is obtained, many patients tend to drop out of the study, being lost to follow-up. In the present study, only four patients did not answer the questionnaires when they were reapplied, and the $8 \%$ dropout rate probably had a negligible negative effect on the results. However, following the Consolidated Standards of Reporting Trials (CONSORT), the data about those patients were included in the data analysis, which was based on intention-totreat. Another limitation of this study was that the participants were predominantly young and undergraduate students. Considering that esthetic perceptions are strongly related to age and sociocultural levels, our findings may not be replicated in studies with older patients or with those from a different sociocultural level. Finally, it should be noted that the questionnaires used were not developed to evaluate the impact of tooth bleaching, and also that the development of more specific questionnaires could increase sensitivity in evaluating patients' perceptions of dental bleaching. 


\section{CONCLUSION}

Despite only to modify the tooth color, inoffice bleaching procedures were able to improve the overall perception of patients regarding their dental esthetic.

\section{REFERENCES}

1. Koidou VP, Chatzopoulos GS, Rosenstiel SF. Quantification of facial and smile esthetics. J Prosthet Dent. 2018 Feb;119(2):270-7.

2. Shulman JD, Maupome G, Clark DC, Levy SM. Perceptions of desirable tooth color among parents, dentists and children. J Am Dent Assoc. 2004 May;135(5):595-604.

3. Alkhatib MN, Holt R, Bedi R. Prevalence of self-assessed tooth discolouration in the United Kingdom. J Dent. 2004 Sep;32(7):561-6.

4. Alani A, Kelleher M, Hemmings K, Saunders M, Hunter M, Hunter M, etal. Balancing the risks and benefits associated with cosmetic dentistry - a joint statement by UK specialist dental societies. Br Dent J. 2015 May 8;218(9):543-8.

5. Kershaw S, Newton JT, Williams DM. The influence of tooth colour on the perceptions of personal characteristics among female dental patients: comparisons of unmodified, decayed and "whitened" teeth. Br Dent J. 2008 Mar 8;204(5):E9, discussion 256-7.

6. Meireles SS, Goettems ML, Dantas RVF, Bona Á Della, Santos IS, Demarco FF.Changes in oral health related quality of life after dental bleaching in a double-blind randomized clinical trial. J Dent. 2014 Feb;42(2):114-21.

7. Eimar H, Siciliano R, Abdallah MN, Nader SA, Amin WM, Martinez PP, et al. Hydrogen peroxide whitens teeth by oxidizing the organic structure. J Dent. 2012 Dec;40 Suppl 2:e25-33.

8. de Geus JL, Wambier LM, Kossatz S, Loguercio AD, Reis A. At-home vs Inoffice Bleaching: A Systematic Review and Meta-analysis. Oper Dent. 2016 Jul-Aug;41(4):341-56.

9. Demarco FF, Meireles SS, Masotti AS. Over-the-counter whitening agents: a concise review. Braz Oral Res. 2009;23(Suppl 1):64-70.

10. Rezende M, Loguercio AD, KossatzS, Reis A. Predictive factors on the efficacy and risk/intensity of tooth sensitivity of dental bleaching: A multi regression and logistic analysis. J Dent. 2016;45:1-6.

11. Bernardon JK, Ferrari P, Baratieri LN, Rauber GB. Comparison of treatment time versus patient satisfaction in at-home and in-office tooth bleaching therapy. J Prosthet Dent 2015;114(6):826-30.

12. LiY. Toxicological Considerations of Tooth Bleaching Using PeroxideContaining Agents. J Am Dent Assoc. 1997;128(April):31S-36S.

13. Paravina RD, Ghinea R, Herrera LJ, Bona AD, Igiel C, Linninger M, et al. Color difference thresholds in dentistry. J Esthet Restor Dent. 2015 Mar-Apr;27 Suppl 1:S1-9.
14. Martin J, Rivas V, Vildósola P, Moncada L, Oliveira Junior OB, Saad JR, et al. Personality style in patients looking for tooth bleaching and its correlation with treatment satisfaction. Braz Dent J. 2016 Jan-Feb;27(1):60-5.

15. Espeland L V, Stenvik A. Perception of personal dental appearance in young adults: relationship between occlusion, awareness, and satisfaction. Am J Orthod Dentofacial Orthop 1991;100(3):234-41.

16. Sinhal, Jones L, Smyth RL, Williamson PR. A systematic review of studies that aim to determine which outcomes to measure in clinical trials in children. PLoS Med 2008;5(4):e96.

17. Fleming PS, Koletsi D, O'Brien K, Tsichlaki A, Pandis N. Are dental researchers asking patient-important questions? A scoping review. J Dent. 2016:49:9-13.

18. Schwendicke F, Lamont T, Innes N. Outcomes in Trials for Management of Caries Lesions (OuTMaC): protocol. Trials 2015;16:397.

19. John MT, Larsson P, Nilner K, Bandyopadhyay D, List T. Validation of the Orofacial Esthetic Scale in the general population. Health Qual Life Outcomes 2012;10(1):135.

20. Sperber AD. Translation and validation of study instruments for crosscultural research. Gastroenterology 2004;126(1Suppl 1):S124-8.

21. Peters M, Passchier J. Translating instruments for cross-cultural studies in headache research. Headache 2006;46(1):82-91.

22. Guillemin F,Bombardier C, Beaton D. Cross-cultural adaptation of healthrelated quality of life measures: literature review and proposed guidelines. $J$ Clin Epidemiol 1993;46(12):1417-32.

23. Larsson P, John MT, Nilner K, Bondemark L, List T. Development of an Orofacial Esthetic Scale in prosthodontic patients. Int J Prosthodont. 2010;23(3):249-56.

24. Larsson P, John MT,Niner K, List T. Reliability and validity of the Orofacial Esthetic Scale in prosthodontic patients. Int J Prosthodont. 2010;23(3):257-62.

25. Sardenberg F, Oliveira AC, Paiva SM, Auad SM, Vale MP. Validity and reliability of the Brazilian version of the psychosocial impact of dental aesthetics questionnaire. Eur J Orthod. 2011;33(3):270-5.

26. Samorodnitzky-Naveh GR, Geiger SB, Levin L. Patients' satisfaction with dental esthetics. J Am Dent Assoc. 2007;138(6):805-8.

27. Joiner A. Tooth colour: a review of the literature. J Dent. 2004;32 Supp 1:3-12.

28. Tin-0o MM, Saddki N, Hassan N. Factors influencing patient satisfaction with dental appearance and treatments they desire to improve aesthetics. BMC Oral Health. 2011:11:6.

29. Qualtrough AJ, Burke FJ. A look at dental esthetics. Quintessence Int. 1994:25(1):7-14.

30. Davis LG, Ashworth PD, Spriggs LS. Psychological effects of aesthetic dental treatment. J Dent. 1998;26(7):547-54.

31. Anderson SL, Adams G, Plaut VC. The cultural grounding of personal relationship: The importance of attractiveness in everyday life. J Pers Soc Psychol. 2008;95(2):352-68.

\section{Prof. Dr. André Luis Faria-e-Silva} (Corresponding address)

E-mail: fariaesilva.andre@gmail.com

Departamento de Odontologia, Hospital Universitário, Rua Cláudio Batista s/n, Bairro Sanatório, Aracaju, SE, CEP 49060-108, Brasil.

Date submitted: 2017 Feb 27

Telephone: +55 79 3194-7220. 